\title{
Exploiting the Sustainable Development of Competitive Sports in the View of Sociology
}

\author{
Jing Gao \\ School of Physical Education, Changzhou University, Changzhou, China \\ E-mail: 284611656@QQ.COM
}

\section{Keywords: Sustainable Development; Humanism; Competitive Sports; Human Being}

\begin{abstract}
From the perspective of sustainable development, this paper analyzes and studies the dialectical relationship between the sustainable development of competitive sports and sustainable development of human being, nature, economy and society. The results shows that in order to really achieve sustainable development of competitive sports, researchers should not only concern the maintenance and utilization of natural environment, but concern more about the transformation of natural environment and try the best to build a natural ecology with more humanity, and seek to create a better atmosphere of race, survival conditions and survival environment; the development of competitive sports depends on the strong economical basis ,and it will react to the economy and promote the sustainable development of economy; competitive sports is miniature and focus of the society, it is also a impeller for the sustainable development of society, it can make the society have more vigors, vitalities, health and civilization.
\end{abstract}

\section{The Background of the Theory of Sustainable Development}

Historical origins of the concept of sustainable development can be traced back to an International Conference in April, 1968. Since then, the "human-oriented" humanism gradually takes root in the modern society. With a doubt of "is there any developing limits for human being?" an Italy Economist Dr aolailiou Peiqieyi has convened scientists from different disciplines to establish an informal international organization the world famous "Club of Rome", and published their report openly in 1972 - The Limits to growth. The report believed that natural resources that could be used by human was limited, and there were limits to growth; what could be unlimited continued to grow were human activities that did not need a lot of resources irreplaceable, or did not produce severe environmental degradation. Especially those that were considered as the best and most satisfying human activities, such as education, art, music, religion, basic scientific research, physical activity and social interaction, could be thrived. The report not only confirmed people's spiritual needs, but also took an optimistic view toward the spiritual development; for science and technology, the Club's members with strong humanistic spirits believed the positive and negative roles of S\&T, for example, they believed that the side-effects of the green revolution was inclined to expand the inequality between man and man. Thereafter, in the book of blueprint for survival by Oliver Goldsmith, U K, in the only one Earth and sand, United Nations General Assembly, Stockholm, in the book of human being at a turning point by Norwich all proposes early warning and response on the future of humankind from a variety of perspectives.

In the 1980s, the well- accepted "sustainable development theories" was published formally. In 1983, United Nations proposed the concept of "comprehensive development", whose key idea was the cooperation evolution of economic growth and social development, then Norway's Prime Minister Gro Harlem Brundtland was appointed as the President of the "World Commission on environment and development" (WCED) and proposed a "global innovation agenda" to search basic measures of the future development of mankind. In 1987, WCED announced the "our common future", which proposed formally the internationally recognized theory of "sustainable development". The Committee believed that sustainable development not only met the 
contemporary needs but also met the needs of the offspring without harm to their developing capacity. The core of the theory was to keep the balance between man and nature; to make efforts to achieve the harmonious relationship among human. The former refers to the dependence of human and nature. On one hand, as a living organism, human being needs the material to sustain life activities, and carry out the exchange of materials with the nature to be survival. However, the Nature is not ever-young, and it has limited life. If researchers indulge in excessive exploitation of natural resources, it will be depleted of exhausted early, then human being would be determined to suicide. On the other hand, due to the existence and development of human, nature adds unlimited vigor and vitality. The succession and evolution of human social activities and production activities play a decisive role in the evolution of natural environment. Therefore, researchers must strive to seek evolution between man and nature, in order to achieve a harmonious union lasting for a hundred years. The latter requires good layout of the tension and confrontation relationship between present generation and intergeneration. For the present generation, the development of any nations and areas should adopt the principles of "collaborative development", and should not develop at the cost of damaging the interests of other national and areas; for intergeneration, development should reflect the "persistent" principle, that is to say, the development of contemporary people should be on the premise of not harming the benefits of future generations.

After entering the 1990s, the theory of sustainable development is gradually mature and perfect, the basic concepts and strategy of the sustainable development have been widely recognized by many nations and many international organizations, and human-oriented humanism has become the main theme of the times. The world's population and development conference held in 1994 clearly pointed out that "the substantial issue of sustainable development is human". In 1995, the senior conference of the United Nations on the word population and social development indicated "we should put the human at the core position of development". The Chinese government also made a positive response to this issue, "China's Twenty-first Century Agenda" proposed the important concept of "people-oriented sustainable development"; "Report of the Development of Chinese Society" had also put forward that "human is the core of social development". The Chinese society gradually formed a consensus as the following: The core of sustainable development is the comprehensive development of human being itself, it serves for human being and the sustainable development must be fulfilled by the all-perspectives development of people.

In a word, the theory of sustainable development with humanism is an all-round development with the main line of evolution of society as a whole, what it pursues is to meet people's demands in many aspects (such as material needs, spiritual and cultural needs and the needs of the ecological environment) and the all-round development of people, and its ultimate aim is to improve and enhance the quality of human life and living environment.

\section{The Sociological Thought on Sustainable Development of Competitive Sports}

Competitive Sports and Nature. Athletic sports and the natural environment are closely associated. To carry out sports activities, it should be based on the natural environment, but it also reacts to the environment. The Sports Charter formulated by UNESCO pointed out: "Conceding combining sport and natural environment make sports rich and colorful, arouse the respect for the earth's resources and to care for the greater benefit of the entire human, researchers should protect and use these resources. At a certain extent, sports is the return of human behavior and activities to nature, and researchers were able to enjoy the thrill of the biological instinct of human in nature. With the clean air, blue skies, rich forests, vast prairies, vast sea and steep mountains, sports activities can develop better. The natural factors are involved in the ecological sports, leisure sports, green sports, and extreme sports. All these sports lead the new fashion of the new century. And rowing, swimming, climbing, surfing and skïng are the new darling of the masses due to the full integration with natural ecology. 
While sports return to nature, the conflict between sport and natural ecological environment has aroused wide concerns. Taking into account the previous damage made by the Olympic Games to the local natural environment, the International Olympic Committee had put forward a series of environmental protection measures and policies, and on the first conference of sport and the environment held in Lausanne, Switzerland on 7, July, 1995, clearly regarded environmental protection as one of the millstones of the Olympic spirit. year, In Olympic 21 century agenda published by the International Olympic Committee, 1999 also pointed out that the development of Olympic sports should promote global sustainability and environmental protection. The Vice President of International Olympic Committee, Schmidt said, "except for sports and culture, environmental protection has become the third meaning of the Olympic movement." As an important part of the sustainable development strategy, the operation and development of competitive sports should on the basis of natural conservation, make efforts to seek harmony with the natural environment. In detail, Olympic games and other large sports events should keep a limited scale; the increasing and deletions of sports projects should depend on whether it is beneficial to ecological protection and natural maintenance; the development of sports tourism and sports entertainment activities should avoid damages to the ecological system and pollution to environment, the cycle using and recycling of waste items should be encouraged, the exhaust emissions pollution of cars and other transportation vehicle s should be reduced to minimum level; the planning and construction of sports facilities and sports venues should not only follow theme of the environmental protection, but take into account the long term sustainability; not only occupy undeveloped land as little as possible, but try to avoid the destruction of the green vegetation and create a better living space. It is important to note that, in order to realize sustainable development of competitive sports, the key problem is not only simply to maintain and utilize the original natural environment, but more important to transform the nature with practical activities, to build a more humanism natural ecology and to create a better competitive atmosphere, living conditions living environment.

Competitive Sports and Economy. Economic activity is a fundamental human social activity as well as the basis of existence and development of human society. The implementation and development of competitive sports depends on the material wealth provided by economic production and it must be affected by economic constraints. At first, competitive sports are restricted by the economic conditions. In a labor-dominated agricultural society, economic and social productivity levels are very low, heavy physical labor has made people suffer from pain, and it is impossible for competitive sport existing as an independent socio-cultural pattern. After entering the industrial society, with the progress in production capacity and technology, the presence of seeds of Western market economy, social production and way of life changed greatly. It promotes a new awareness and demand for sports and modern sports come into being at that time. Nevertheless, at that time, in the Western, it is a privilege of noble and leisure social class to enjoy competitive sports. On the threshold of the era of modern society, with the rapid development of information technology and the media industry, rapid improvement in people's living standards, as well as the increase in leisure time, the development of competitive sports relies on the social material wealth and reach to an unprecedented heights. It has been widely involved and recognized in modern society. Secondly, the development of competitive Sports is restricted by the level of economic development. From the vertical view, accompanied by a historical step forward, raising the socio-economic level, competitive sports came into being from nothing stage to junior and senior stage, from single form to a rich and colorful form. From the perspective of horizontal, the development of competitive sport is thriving in Western developed countries, who has dominated the sporting supremacy in the world, while in poor countries of Latin American and Asia-Africa because of the weak provision and manpower, it is hard to find their traces in the Medal tally. Thus, it is obviously that the development of competitive sports is based on strong economic foundation, and its sustainability depends on sustained and coordinated economic growth in every country, region in the world. 
Of course, sports also will work against the economy, promote sustainable development of economy and promote their sustainable development. On one hand, development of competitive sports can promote the growing mode of economy. According to theory of sustainable development, researchers must change the past mode of simple relying on consumption of huge amount of resources to the mode of reducing environmental hazards as many as possible, and make efforts to create good natural ecological environment, form two-way interactive new relationship between people and natural; change simple concept of pursuing economic and ignoring ecological and social, combine up production and ecology organically and form the production mode to the needs of meet modern development, that is ecological economy. Competitive sports industry as a green, pollution-free, new economic models of resource conservation, is consistent with the requirements of sustainable development, will give a strong impetus to the variation of economic growth pattern. The other hand, the development of sports can promote the economic growth obviously. In the West advanced capitalist countries, due to the eerily adoption of professional sports, commercially matured competitive sports industry had occupied the king position of global sports market, been the pillar industries in the service industry, harvested enormous social and economic benefits for the country. In China, the sports industry is in childish stage, but researchers are facing with good opportunities to develop. China's economy is moving from "labor-oriented economy to a" leisure-oriented economy". At this stage, from the consumer's perspective, the demand for material goods will diminish and for consumer services, goods, especially spiritual entertainment related to people's health and quality of life will rise quickly. Competitive sports will meet these needs in its unique charm. Furthermore, with the increasing of the GDP of the continue, increasing of income level and the accelerating process of urbanization and so on, all provides a "catalyst "for the rapid development of the Chinese competitive sports industry. Predictably, the development of competitive sports as an engine in the sports industry will become an important power to promote the sustainable growth of the national economy, sport economy in which competitive sports accounts for a large proportion will be the new growing point of the national economy. In any case, researchers must realize that the economic growth is only a means, and it must serve for survival and development of human.

Sports and Society. Sociologists believe that sports (including competitive sports) are a miniature and focus of society. Since competitive sports began, it compared physically exercise capacity among people, and it is closely linked with the social activities. It concentrated the reflection of individual needs him certain period, and needs of mass and society; it reflected people's value pursuit and value concept; it was the concentrated mapping of people's life style and social system; it mutually interwove ned with economy, political, technology, military, art, religious and other social factors; it accompanied end together with movement and still, justice and evil, competition and collaboration, and other social contradictions. Competitive Sport is always linked with the external social conditions, which determines that the sustainable development of competitive sports is restricted by the sustainable development of society.

Competitive sports are also accelerated to develop in a sustainable manner, and it makes the society more vigorous and vital, healthy and civilized. First of all, competitive sports inject the spiritual concept of fair competition into the society. Due to the influence of Confucian culture, Chinese society not only has been advocating the "harmony is precious" since the ancient times, but also emphasizing the social class and repelling competition. It seriously hindered the development and progress of society. In contrast, although competitive sports acknowledges the inequalities in personal natural ability, it secures everyone have the equal interest to participate; although competitive sports pay attention to the inequality in competition results, it ensures the integrity in the competitive process. Therefore, the development of modern competitive sports in China is helpful for people to discard traditional stereotypes and to foster the competitive spirit that is needed for the development of market economy. Secondly, competitive sports create the social rules and democratic consciousness for the society. Long-term feudal Chinese society poisoned Chinese people with the absolutism. "The supremacy of the King" and "big guy's words" not only destroys the social democracy, but makes the 
society lack strict social regulations. Due to lack of "written rule", many disputes are often resolved impulsively and sentenced randomly. Competitive sports were recognized as the Community rules (such as competition rules, referee rules, etc.), and it had been regarded as a glorious example of democratic procedures, was a symbol of social civilization and progress. These rules permit us to carry out competitive sports "by the law and under the law", provides the fundamental principles for referee disputes, arbitrating awards, form a kind of social contracted relationship between people. Thirdly, as a power to enhance social integration, Competitive sports are beneficial to maintain social order and social stability. This power can effectively put the dispersed and potential members of society together. Watching sports games make people of different ages, genders, races, cultural backgrounds linked together, they often generate a strong collective sense of community, national identity, sense of belonging and sense of honor for the same common interests, hobbies. Meanwhile, watching a sport match is functioning as pressure - relief valves because the audience can relieve their negative emotions (such as depression, frustration, dissatisfaction with the economy, work, etc.). All of these not only play a positive role in the maintenance of social order and social stability, but also provide a good environment for the sustainable development of society.

\section{Summary}

In short, the sustainable development is the inclusive and harmonious development of nature, economy, society, population, resources and et al, on the premise of "people-oriented" rule. As an important component of sustainable development, sustainable development of competitive sports should be complementarily and mutually reinforced, and collaboratively developed in the above mentioned field.

\section{Acknowledgement}

This work was supported by Administration of Sports in Jiangsu under the grant ST1330029.

\section{References}

[1] Zhou Guangzhao, Niu wenyuan, Sustainable development strategy in China, Xiyuan Publishing House, Beijing, 2000.

[2] Wu Jisong, Knowledge economics, Beijing Science and Technology Press, Beijing, 1999.

[3] Lu Yuanzhen, Social culture of sports .. Beijing sports University Publishing House, Beijing, 1998.

[4] Zhu Desheng, Survival and development issues and sustainable development, Journal of Huazhong University of Science and Technology Edition of Social Sciences. 1(2002)1-6.

[5] Luo Haobo, The multi-dimensional implication of sustainable development and its trend, Journal of Baoji College of Art and Science (Social Science). 22(2002)15-21.

[6] Bao Mingxiao, Status of sport in the social and economic development in the new century . Journal of Tianjin Institute of Physical Education. 16(2001)4-6.

[7] Shen Jianyong, Development of nano-technology brings to the sport's ethical problems and countermeasure research, Journal of Sports and Science. 2(2001)14-16.

[8] Wu Yanbo . Analysis of the third Olympic Games connotation-environmental protection, Journal of sSports and Science. 4(2001).12-13,3.

[9] Information on http://www.qq.com

[10] Information on http://www.xinhuanet.com 